\title{
Cross-docking project: a case study
}

\author{
C. Paciarotti ${ }^{1}$, F.E. Ciarapica ${ }^{1}$ and G. Giacchetta ${ }^{1}$ \\ ${ }^{1}$ Dipartimento di Energetica \\ Università Politecnica delle Marche, Ancona, \\ (Tel: +39071 2204696, Fax +39 0712204770 , e-mail: c.paciarotti@univpm.it, f.ciarapica@univpm.it, \\ g.giacchetta@univpm.it )
}

\begin{abstract}
In this work a case study is proposed in order to define the main steps carried out to design a cross-docking in Fano, a city located in the centre of Italy, in Pesaro-Urbino province. The cross-docking project analysed in this work is made up of four steps:

- first of all an analysis of the main parameters that characterize a cross-docking was carried out;

- region characterization: economical and environmental analysis;

- road traffic analysis of goods for the geographical area considered;

- demand analysis of a sample of firms (factory firms and freight operators) using questionnaire; analysis of results.

Results obtained from this work show that the cross-docking allows economic improvements and pollution reduction.
\end{abstract}

\section{Key words}

Cross-docking, Pollution reduction, Sustainable Development, Road Traffic Reduction, logistic management.

\section{Introduction}

The data about Italian Energetic consumption, elaborated by Ministry of the Production Activities, highlight that the transport sector absorbs a percentage value of 32.7 on total national consumption of energy.

The distribution of energy consumption between the different transport methods is: $83.6 \%$ associated with road transport, $7.6 \%$ with air transport, $7.1 \%$ naval tanks (connected with fuel necessary to supply propulsion to ships), $1.2 \%$ with transport by rail and $0.5 \%$ with transport developed on waterway. An analysis regarding energetic sources used by transport means, highlighted the total dependency on petroleum products (mainly gasoline and diesel)[1]. It is obvious that an improvement of the efficiency about road transport of goods is the key to reduce energetic consumption, carbon dioxide, environmental degradation and freight costs. Italy because of its geographical position in Mediterranean sea, because of its shape, because of its industrial structure (mainly based on small and medium firms), needs to develop a more efficient transport systems of goods with reference to international, national, regional and urban scale. It is possible to carry out these aims with a rationalization of transport means that work on long distances and thank to interchange points like crossdocking. It is necessary to improve the collection phase of goods and their distribution on regional and urban scale.

Cross-docking is a relatively new logistics system used in the retail and trucking industries to rapidly consolidate shipments from disparate sources and realize economies of scale in outbound transportation. Cross-docking essentially eliminates the inventory-holding steps of a warehouse while it allows to serve the consolidation and shipping functions. The idea is to transfer incoming shipments directly to outgoing trailers without storing them in between. Shipments typically spend less than 24 hours at the facility, sometimes less than an hour.

The improvements that are possible to obtain from crossdocking are important not only from economic point of view but also it gives the possibility to produce a reduction of noise pollution, road accident and urban blight.

\section{Region characterization: economical and environmental analysis}

Fano is located in the centre of Italy and it is well connected with the most important Italian city, not far (less than $60 \mathrm{~km}$ ) from important airports and harbour. Even if Fano is located in a strategic position, the area is caractherized by a low "Economic Structure Allocation Index" value. This index represents the total qualiquantitative allocation of road, railway, harbour and airport facilities in a defined zone. Moreover the index takes into consideration environmental-energetic, post office, bank and broadcasting structures.

The province analysed in this work is characterized by an economic infrastructure index of 69.5 while the national average value is 100 . This is a measure of how important are logistic infrastructures in this province. Taking into consideration only the index referred to road, the index is greater than national value (108,1 against 100).

In the Fano city, the great traffic flow produces an important air pollution. Fig.1. shows how, in 2006, there 
were an high number of cases of exceeding of the limit value of $50 \mu \mathrm{g} / \mathrm{m}^{3}$ of PM10.

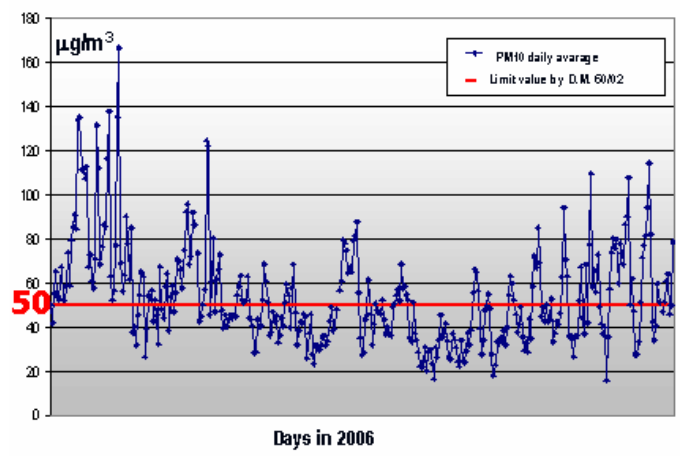

Fig.1 PM10 daily average value

Data analysis proves that 177 days in an year the limit values were exeeded. According to the Italian law "D.M. $60 / 02$ ", only 35 cases in an year are allowed. These vales show the seriousnees of the situation from air pollution point of view.

It is imprtant to note that from 2004 to 2006 the pollution conditions seem to be aggravated: 147 exceeding cases of $50 \mu \mathrm{g} / \mathrm{m}^{3}$ in 2004, 163 in 2005 and 177 in 2006.

Moreover the nitrogen dioxide $\mathrm{NO}_{2}$ also shows an annual average value of $48,8 \mu \mathrm{g} / \mathrm{m}^{3}$. This value is higher of limit of $40 \mu \mathrm{g} / \mathrm{m}^{3}$ that will come into effect from 2010 (at the moment the standards are less restrictive with a limit of $\left.54 \mu \mathrm{g} / \mathrm{m}^{3}\right)$.

Fig.2. defines the most important industrial sector in the region studied that could be interested in cross-docking project [2].

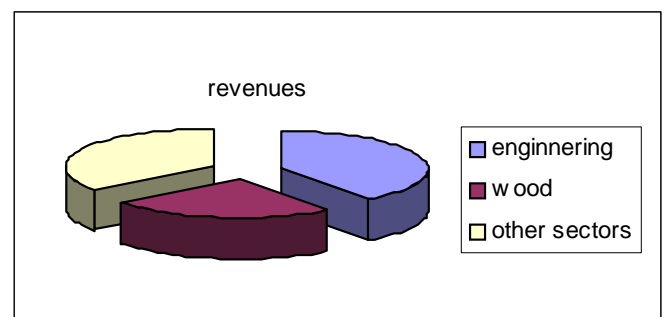

Fig. 2. Revenues divided from industrial sector

The $40 \%$ of total revenues come from engineering firms and $25 \%$ from wood forms. The same values can be obtained considering the personnel employed.

Moreover in Fano the shipbuilding industry has an important role from National and International point of view: $15 \%$ of the total national production is realized in Fano.

The trasport costs of Fano firms are an important part of the total costs. The reasons of this impact of transports come from several factors:

- The transport firms are predominantly one-man companies and so they are less competitive from international point of view;
- The international trade services supplied by transport companies are insufficient and not integrated;

- National infrastructures are inadequate and scarce in order to manage the increasing international trade.

\section{Freight traffic by road analysis}

An exhaustive study of freight traffic by road in the city of Fano was carried out in order to have a clear view of the existing situation and a quantitative assessment of the advantages of cross-docking creation. At First the study has been carried out at the regional [3] and provincial level [4] and then locally [5]. Regarding Marche Region, the following values has been identified:

- composition of the firm car fleet;

- third party transportation percentage;

- the total transportation by road that have Marche Region as destination or provenance;

- the same total transportation divided by products macro-branches;

- infrastructure indexes.

Many firms, in Marche region, prefer to organize alone the goods transport (Fig.3.). In comparison with Italian values, it is possible to highlight that in Marche $35,7 \%$ of total goods are sent by oneself, against the national value of $30,8 \%$. Considering as measurement unit the tons moved per covered kilometres there is a reduction of thiese values: in Marche the $14 \%$ of goods are transported by the firms against a national value of $10,8 \%$.

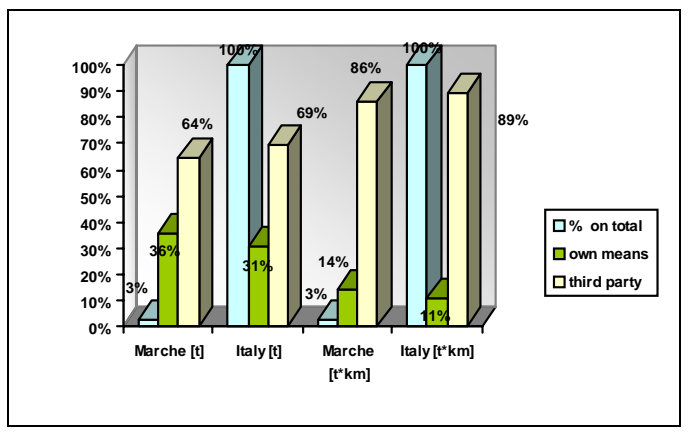

Fig.3. Percentage of goods that have Marche region as origin (percentage values on tons and ton $\mathrm{x} \mathrm{km}$ ) compared to average Italian values

An analyses of the data, collected during this work, show that the main freight is concentrated inside the region, while other important flow takes into consideration the Emilia Romagna, Umbria and Abruzzo regions, as it is possible to see from Fig.4. 


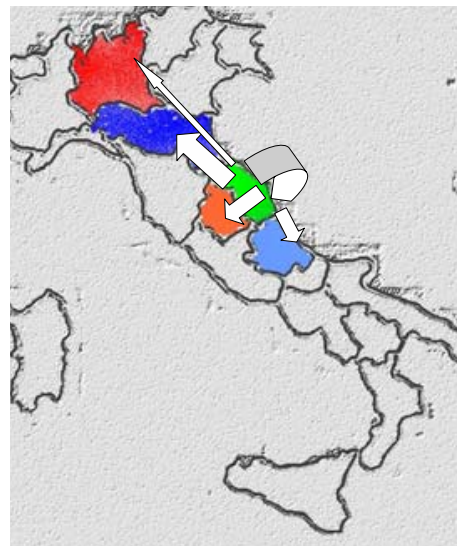

Fig.4. Road freight flow greater than 1 milion of tons that has their origin in Marche

Similar results has be obtained considering the Marche region as destination.

Regarding Pesaro and Urbino Province has been identified:

- the transport by road companies divided by employees number;

- the equipment of infrastructure index;

- the traffic congestion level on provincial and state road.

Finally, regarding the city of Fano, the quantitative assessment of freight traffic flux that a cross-docking can draw has been realized. The freight traffic has been analyzed in two nodal points: the A-14 tollgate and state road E78 (Fig.5.).

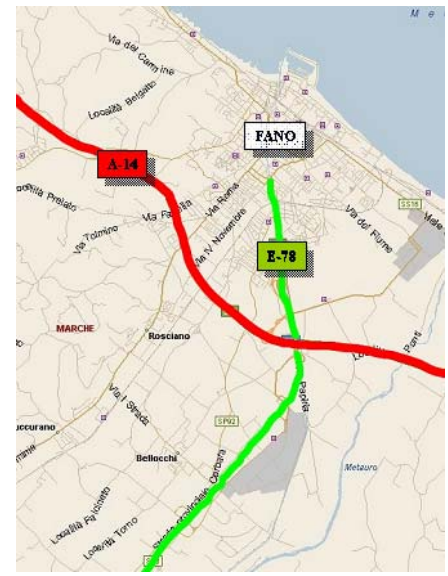

Fig.5. The two nodal points: the A-14 tollgate and state road E78

The first one is important because it is the connection basis with the only highway in Marche Region along the Adriatic coast in north-southbound. The second one is important because it crosses the industrial area and it is the most important north-south thoroughfare of the city.
In quantitative terms, considering the most heavy transport means, it is possible to evaluate the following values for A-14 road.

- Class 3 transport means (car with van, autobus, truck, articulated lorry, ...); 54.000 means in 2000 and about 85.000 means in 2006 have been registered in inbound;

- Class 4 transport means (car with van, autobus, truck, articulated lorry, tractor-trailer, ...); from 30.000 means in 2000 to 18.000 means in 2006;

- Class 5 transport means (articulated lorry, tractor-trailer, ...); from 150.000 means in 2000 to 220.000 means in 2006 .

Every transport mean has, in some way, its own seasonal demand that is possible to evaluate from data collected in our research. Fig.6. shows the inbound freight traffic per month of class 5 transport means in the years 2003 and 2006.

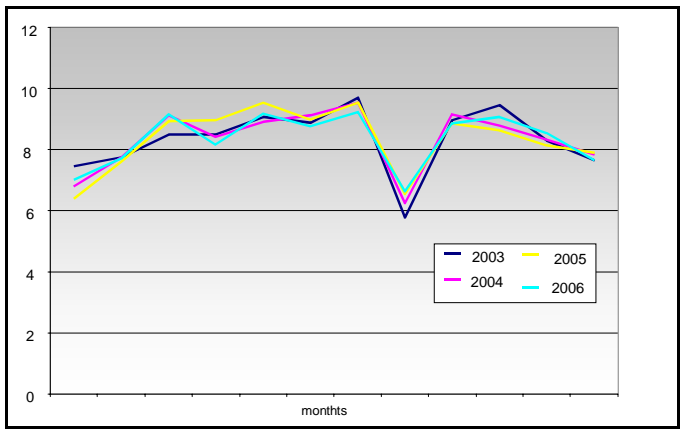

Fig.6. Class 5: development of freight traffic in A-14 tollgate from 2003 to 2006

The evaluation of peak on graph is useful to design the cross-docking.

The analyses show that the territory is characterized by an heavy freight traffic. Referring at 2006 , the total amount of heavy vehicle movement is 626,000 (sum of tollgates input and output) at tollgateand and 976,000 (sum of flows in the two lane) at E78.

It is clear that an elevated flow of freight traffic is associated to an elevated demand of logistic services.

\section{Questionnaire}

A questionnaire has been developed to collect information about organizational structure and operational requests of freight transport in Fano; the obtained information support for the statistical and mathematical analyses and confirm the results previously obtained. The questionnaire main scope has been to investigate:

- the main demand features, as elements to evaluate the economical convenience of a crossdocking creation;

- companies and transport operators' interest and subjective willingness to cross-docking services, 
let alone their opinion on advantages from cross-docking using;

- logistic and transportation problems that could be solved or reduced by using solutions given by the cross-docking.

Two distinct questionnaires has been realized because of the different features of business and transport operators.

\section{A. The sampling}

A proportional stratified sampling with a $95 \%$ confidence interval and a $7.5 \%$ level of significance has been used [6]. At first a complete list of Fano companies has been gathered from Ancona chamber of commerce. Only the most important sectors and compagnies concerning the freight traffic creation has been considered for the questionnaire. Companies with less than 3 employers and retailers has been excluded. The considered sectors has been: farming, fishing, mineral processing, manufacturing, wholesale trade and road haulage.

\section{B. Questionnaire results}

\section{Relocation}

| The 7\% of transport operators moved the headquarter from the same region to the actual location, for locistic problems. This percentage is composed by specilized transport operators, with in average ten employers, which focus on logistics.

The $31 \%$ of companies moved the headqurter; between them $99 \%$ moved from the same province and $1 \%$ from the same region. The reason of relocation is not to corner a new marke but for logistic problems (39\%) and market expansion $(61 \%)$.

These values show the presence of logistic problems in this area.

\section{Computer development}

Only $37 \%$ of transport operators use a personal computer, between them $90 \%$ has an internet connection and $13 \%$ use a logistic software.

The $87 \%$ of companies use a personal computer, between them $91 \%$ has an internet connection and $40 \%$ usa a logistic sotware.

These alarming data point out a limited technological development. In transport environment lead time and demand-request coordination must be fast and travels and loads organiziation is on the basis of an efficient system. In this kind of environment it is not possible to avoid using specific computer softwares.

The limitated knowledge and the scant propensity to information mediums is mainly proper of transport operators which are owner and driver of the vehicle. They usually try to be competiting throught self exploitation.

Vehicle possessed

The vehicles age has been analized and it is represented in Fig.7.

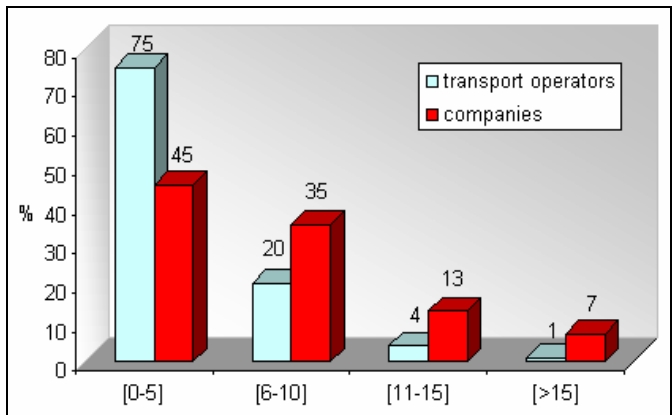

Fig.7. Fleet of vehicle age

The 75\% of transport operators' fleet of vehicles iscomposed by youth vehicles, instead $25 \%$ is composed by vehicles that don't have the modern and efficient antipollution systems. Companies have the worst situation: $55 \%$ of vehicles has more than 5 years.

The situation should invite Public Authority to provide incentives to stimulate firms to buy new vehicles, more efficient and with best results in term of air pollution.

Quantitatively the fleet of vehicles is mainly stationary, this confirms that freight transport sector in Fano lies still and only few firms fuond recently (Fig.8.).

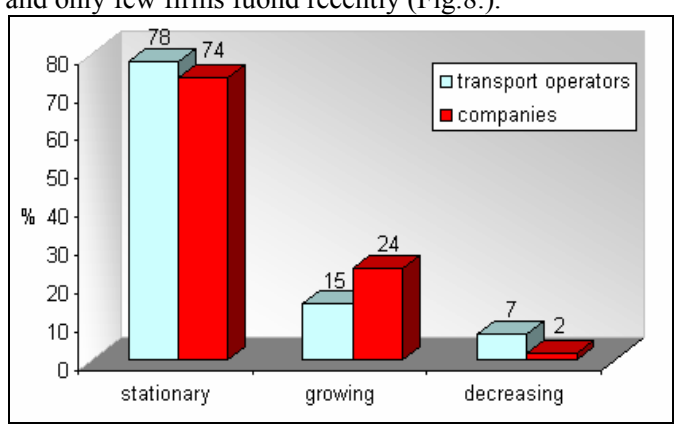

Fig.8. Fleet of vehicle variation

Between trasport operators the bigger size firms, that don't deal only with transport but with logistic service too, invested money recently. The reason that make possible to these firms to grow up is the increase in "service request" number.

On the other side, the reasons than make transport operators and companies fleet of vehicles stationary or decreasing are the competition (mainly with transport operator from Eastern Europe) and the absence of logistic structures.

A crossdocking could introduce valuable improvement and stimulate freight transport sector grow up.

Auxiliary services provided by transport operators

Data collected show that in Fano the concept of logistic is strinctly linked with transport service. 


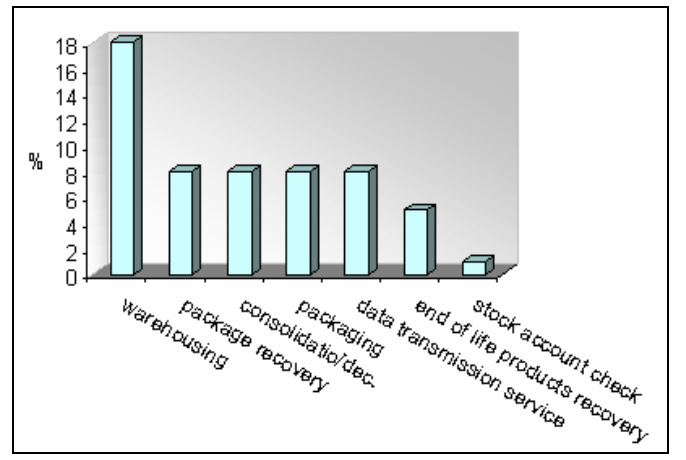

Fig.9. Auxiliary services provided by transport operators

Apart from the service of warehousing provided by $18 \%$ of transport operators, only less than $10 \%$ of transport operators provides integrated services as freight consolidation and deconsolidation, loads packaging, data transmission service connected to customer and stock account check.

\section{Transport mode}

The freight transport mode almost exclusively used by Fano transport operators is the road, only 3\% of transport operators state to use intermodal freight transport, in particular road-air and road-water.

Companies show the same prevalence of road monomodal transport, but there is too a $9 \%$ of intermodal road-water transport, a $4 \%$ road-air and a $2 \%$ road-rail.

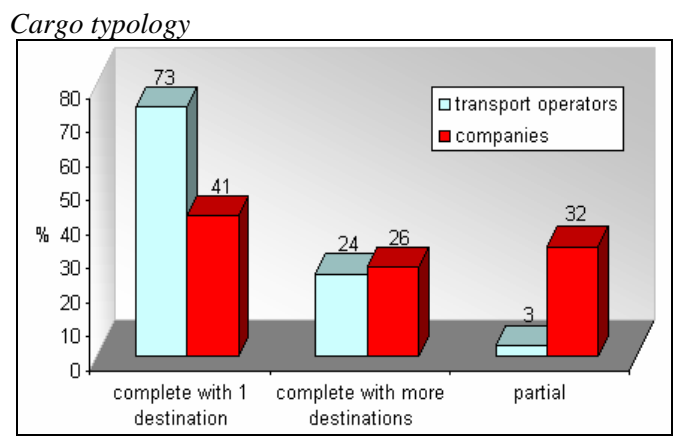

Fig.10. Cargo typology

Transport operators mainly deal with complete cargos from a unique origin to a unique destination (73\%). There are few complete cargos that have more than one destination. This is symptom of limitated transport organization and low logistic development. In fact, to organize a complete cargo with a unique origin and a unique destination is easier than to consider more origins and/or more destinations. This last typology can be reached with good logistic knowledge, which can allow cargo and travel organization and rationalization. Partial cargos represent only the $3 \%$ of total.

Companies present an allarming datumconcerning partial cargos: $32 \%$ of movement are carry out with partial cargos.

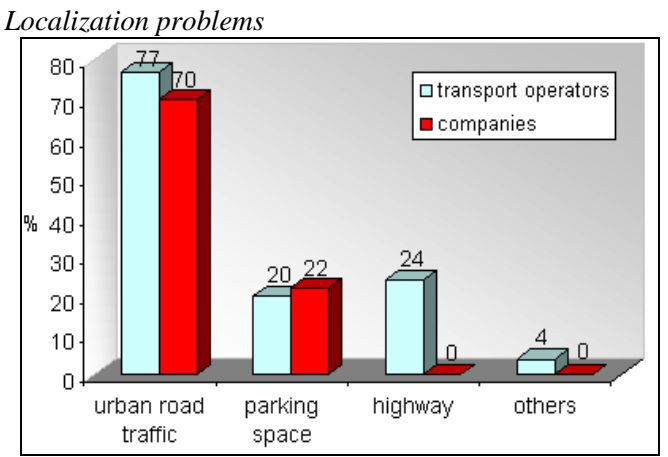

Fig.11. Localization problems

The bigger problem is with the urban roads: to go through and to reach Fano center is really difficult.

Other problems are connected with the highway (for transport operators) that cannot substain the real traffic and with the insufficient parking space.

\section{Logistic problems}

The main logistic problems highlighted by transport operators are the stop necessary for loading and unloading of goods and the trips without load; while the companies highlighted the problems of good storage and good handling into the firm.

Trips without load seem to be an important factor also for the companies even if they consider this possibility more natural. Infact the companies are aware that freight transport is not their core business and that they have not the appropriate equipments and area to carry out these operations.

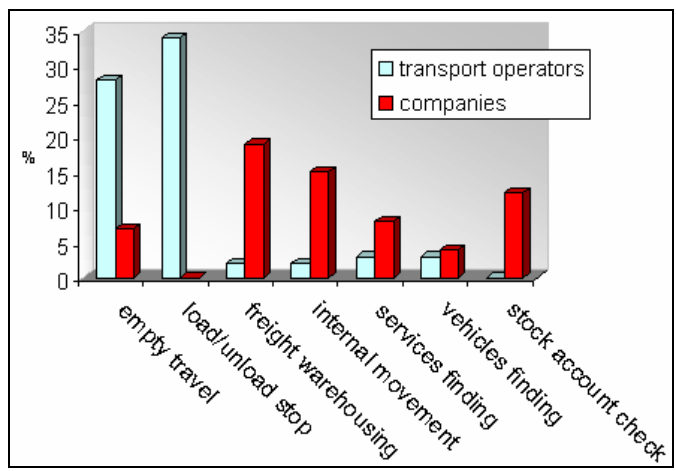

Fig.12. Logistic problems

Cross-docking.

$69 \%$ of transport operators and $48 \%$ of the companies analysed consider very useful the design and construction of a cross-docking. Moreover the stakeholders of this project seem to have a clear idea about the services that the system could offer. 


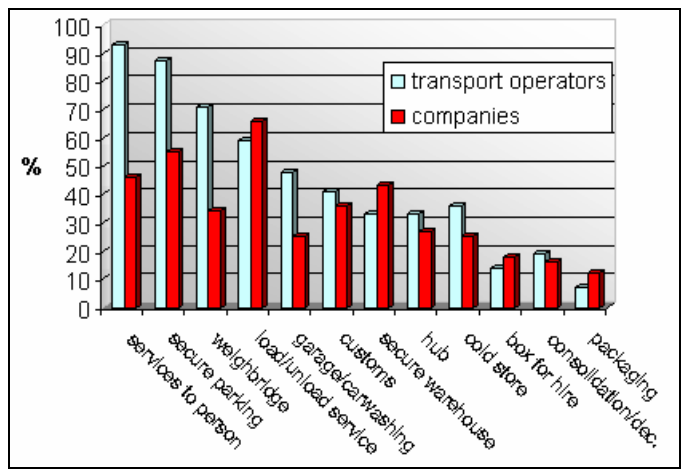

Fig.13. Services required to the cross-docking

Transport operators think that the cross-docking has to offer mainly standard services such as people services (restaurant, bar, showers, toilet facilities, health services, motel, ...), attended car-park, weigh-house, loading and unloading services of goods.

The companies direct their attention to more specialized services of loading and unloading of transport means, attended car-park, people services and attended warehouse. Fig.13. shows that less attention is put on more specialized services that are required in a limited number of cases.

\section{Result analyses and conclusion}

Out of 387 companies analysed in this work, there are 185 companies that are interested to the services offered by the cross-docking. These companies produce a daily freight traffic of 581 vehicles. Taking into consideration the values obtained by the questionnaires, the $32 \%$ of these vehicles have a partial load $(\rightarrow 581 \cdot 0.32=186$ vehicles). Three different scenarios have been taken into consideration in order to evaluate the potential emission reduction of NOx, $\mathrm{CO}, \mathrm{CO} 2, \mathrm{NMVOC}$ e PM10 that can be obtained with a cross-docking:

- scenario 1: partial load of companies equal to $25 \%$; - scenario 2: partial load of companies equal to $50 \%$; - scenario 3: partial load of companies equal to $75 \%$.

TABLE I.

\begin{tabular}{|l|c|c|c|}
\hline & Scenario 1 & Scenario 2 & Scenario 3 \\
\hline Partial load & $25 \%$ & $50 \%$ & $75 \%$ \\
\hline $\begin{array}{l}\text { Decrease of } \\
\text { daily trips }\end{array}$ & $\begin{array}{c}140 \\
{[=186(1-0.25)]}\end{array}$ & 93 & 46 \\
\hline $\begin{array}{l}\text { Decrease of } \\
\text { annual trips }\end{array}$ & $\begin{array}{c}36,680 \\
(=140 * 262)\end{array}$ & 24,366 & 12,052 \\
\hline Decrease [km] & $\begin{array}{c}3,785,376 \\
(=36,680 * 103,2)\end{array}$ & $2,514,571$ & $1,243,766$ \\
\hline $\begin{array}{l}\text { Decrease of NOx } \\
{[\mathrm{kg}]}\end{array}$ & 47258 & 31393 & 15527 \\
\hline $\begin{array}{l}\text { Decrease of CO } \\
{[\mathrm{kg}]}\end{array}$ & 10378 & 6894 & 3410 \\
\hline $\begin{array}{l}\text { Decrease of } \\
\text { CO2[ton] }\end{array}$ & 3724 & 2474 & 1223 \\
\hline $\begin{array}{l}\text { Decrease of } \\
\text { NMVOC[kg] }\end{array}$ & 5627 & 3738 & 1849 \\
\hline $\begin{array}{l}\text { Decrease of } \\
\text { PM10[kg] }\end{array}$ & 2969 & 1972 & 975 \\
\hline
\end{tabular}

Similar evaluations have been carried out for transport operators. These operators have 3,068 trips with partial load. The results obtained are shown in table 2 .

TABLE II.

\begin{tabular}{|l|c|c|c|}
\hline & Scenario 1 & Scenario 2 & Scenario 3 \\
\hline Partial load & $25 \%$ & $50 \%$ & $75 \%$ \\
\hline $\begin{array}{l}\text { Decrease of } \\
\text { annual trips }\end{array}$ & 2,301 & 1,534 & 767 \\
\hline Decrease [km] & 984,368 & 656,245 & 328,123 \\
\hline $\begin{array}{l}\text { Decrease of } \\
\text { NOx[kg] }\end{array}$ & 12289 & 8192 & 4096 \\
\hline $\begin{array}{l}\text { Decrease of } \\
\text { CO[kg] }\end{array}$ & 2698 & 1799 & 8996 \\
\hline $\begin{array}{l}\text { Decrease of } \\
\text { CO2 [ton] }\end{array}$ & 968 & 645 & 322 \\
\hline $\begin{array}{l}\text { Decrease of } \\
\text { NMVOC[kg] }\end{array}$ & 1463 & 975 & 487 \\
\hline $\begin{array}{l}\text { Decrease of } \\
\text { PM10 [kg] }\end{array}$ & 772 & 514 & 257 \\
\hline
\end{tabular}

The following hypothesis have been made in the tables:

- $\quad$ annual working days $=262$

- the average distance per trip is $103,2 \mathrm{~km}$ for company trips, $354 \mathrm{~km}$ for trips in Italy made by third party and $1584 \mathrm{~km}$ for foreign trips made by third party [3].

- emission values per kilometer have been taken from CEPMEIP [7]

- trips made by third party have been divided in this way: $6 \%$ foreign trips and 94\% national trips.

Comparing results obtained by freight transport fluxes analyses and questionnaires, an assessment of market the cross-docking can draw and advantages of cross-docking in term of freight traffic and pollution reduction has been obtained. The cross-docking could give also the possibility to solve some of the most important transport operators and companies' problems like urban road traffic, insufficient parking space and. lack of logistic services.

\section{References}

[1] ISTAT, Statistiche dei trasporti, Annuario n ${ }^{\circ} 5-2007$.

[2] Osservatorio dei Bilanci Aziendali 2008, Decima Edizione, Ufficio Studi CGIL Pesaro, Marzo 2008

[3] ISTAT, Trasporto merci su strada, Anno $2005 \mathrm{n}^{\circ} 10$.

[4] Camera di Commercio Pesaro e Urbino. Servizio Studi e Statistica., Compendio Statistico della Provincia di Pesaro e Urbino. Anno 2005.

[5] Traffic by road data furnished by "Autostrade per l'Italia s.p.a." and "ANAS s.p.a. Compartimento per la viabilità delle Marche".

[6] Luigi Fabbris, L'indagine campionaria. Metodi, disegni e tecniche di campionamento, NIS Roma, 1996.

[7] CEPMEIP Emission factors for particulate matter (Berdowsky J., Visschedijk A., Creemers E., Pulles T., TNO-MEP, NL, 2001. 